\title{
Spraying Devices Design for Simulations of Aerosols and Air Interaction
}

\author{
KHALEEL ABUSHGAIR \\ Mechanical Engineering Department, Faculty of Engineering Technology \\ Al Balqa Applied University \\ Amman, Marka, P.O. box 11134 \\ JORDAN
}

\begin{abstract}
The current work aimed to study and understand the nature of interaction between aerosol/dusts and its surrounding medium such as air and/or solid dry or wet surfaces. Results were used as benchmarks to design spraying mechanisms and devices that can be used for optimizing the spraying device design geometry and shape with adjustable distance between cup and pin in parts and to lower manufacturing cost using solid works flow simulations software. Different spray devices were designed and evaluated with simulation, from simple ideas to complex device shapes. The simulation focused on studying the air profile and stream lines, with and without particles (dust particles with spherical shape and 5 micro meters in diameters), pressure, velocity and density during spraying process. Simulation results for the last modified spraying device case- 6 with mass flow rate of $1.5 \mathrm{~kg} / \mathrm{s}$, and distance between cup and pin of ( part 2) $3.3 \mathrm{~mm}$ showed excellent mixing and spreading mechanisms with uniform velocity of flow, density and pressure through the whole device. Even the tested device in case- 3 with mass flow rate $1 \mathrm{~kg} / \mathrm{s}$, distance between cup and pin of (part 2) $6.6 \mathrm{~mm}$ was also perfect. This device is expected to be used as a nanoparticle spraying device, a pollination device in date palm tree pollination and an aerosols aerodynamic behavior simulating system.
\end{abstract}

Key-Words: Dust; Solid Works Flow Simulations Software, Spraying Device, Nanoparticles, Simulating Aerosols Aerodynamic Behavior, Nanoparticles.

Received: June 1, 2020. Revised: December 3, 2020. Accepted: December 18, 2020. Published: December 31, 2021.

\section{Introduction}

Aerosol is traditionally defined as a group of particles suspended in the air and may come in forms of mists, smokes, sprays, fumes and airborne dusts. Knowing these aerosols, especially airborne dusts, is important due to their contribution to a wide range of occupational diseases such as cancer, asthma, allergies and irritation. Dusts could also be classified according to their origin to minerals (silica), metallic (lead), chemical (pesticides), organic (pollens) and biohazards (moulds) [1-5] . Applications such as indoor/outdoor air quality, medical sprays, thermal sprays and agriculture pollination relay on our knowledge of aerosols aerodynamic behavior and are of high importance. For example, understanding the pollination nature for increasing the productivity of fruits such as date palm tree would contribute to the field of food research. Nanoparticles paint spray machines are another example where energy could be saved if designed well. Furthermore, advanced knowledge of dusts behavior could contribute to better understanding of cancer and asthma diseases and possible ways of managing them [4-7] .

Dusts contain particles with very small diameters ranging from 1 micrometer to around 100 micrometer and could contain salt, heavy metals, nitric acid, organics content, pathogens, dust mites, bacteria, fungi, spores, viruses and anthropogenic among other elements [8-12].

Dust particle sizes are generally classified with respect to their particulate aerodynamic matter (PM) in which diameter size is measured in micrometers $(\boldsymbol{\mu} \mathbf{m})$. The ambient PM concentrations at urban roadways have a strong contribution sources from vehicle exhausts and emissions from tires, brake wear and resuspension of road dust [4].

In order to control and manage aerosols in general and dusts in particular, their aerodynamic behavior should be understood. Experimental investigations are important to highlight the major behavior of dusts and air interactions. However, these experiments have limits that hinder the study of dust aerodynamic behavior of toxic surrounding or biological entity such as human lunges. The other approach used to study dusts aerodynamic behavior is the mathematical approach. Based on the conservation laws of mass, energy and momentum, a set of differential equations is produced. These equations are solved to describe the aerodynamic behavior. However, under turbulent conditions of flow the developed set of differential equations takes a nonlinear form with no analytical solution. 
Therefore, a need to solve such a set of nonlinear equations has caused the science of computational fluid dynamics (CFD) to emerge [ 5-10,16-25] .

Spraying devices are used in multiple applications like industrial, agricultural, domestic upon many others like personal care products. They were designed in a pressurized canister containing volatile organic compounds (VOC) as carrying fluid. They have been commercially used because of their convenience, effectiveness and efficiency in the spray system which is also easy to be used.

VOC contribute to formation of tropospheric Ozone [1-2] . VOC have very big group of Carbonbased chemicals that are easy-to-evaporate at room temperature. Another property is their potential to cause healthy side effects depending on time of exposure. These hazards could be avoided by focusing on developing some air-based aerosol products. On the other hand, the contents still use aerosol more than air or water. some researchers found that the efficiency of aerosol spray had been decreased if the VOC content was decreased [3-5] . To solve this problem and to reduce the environmental effect of it, the improvement of the design of the product should be done.

Aerosols had a pronounced commonalty with $r$ needs the production of portable fine sprays devices. These devices are generally fabricated as atomizer or nozzles with variety of applications. The effective spraying depends on the correct selection of nozzle, pressure and speed. The behavior of the spray aerosol was analyzed by simulation for the improvement of the new future design spray that had similar from the simple functional device to the more functional and complex device. Each design was tested using flow simulations of solidworks package. Test focus on the relation between dust and air flow to get maximum operation functionality and an easy using method, with low cost and manufacturing relations.

\section{SPRAYING DEVICE DESIGN}

In literature, many liquid spraying devices are available but limited devices for air spraying were found. Therefore, design of device that should be simple, functional, effective easy to use, has low energy consumption, light weight and low cost well be achieved.

Several ideas were drawn using solidworks software to find an optimal device. Based on results of different models, device-3 was chosen. Figure 1 represents a sketch of a cross section with $(50 \mathrm{~mm}$ diameter and $100 \mathrm{~mm}$ length).

Device- 3 consisted of 2 main parts with 2 main flow inputs, 2 secondary flow inputs and 2 flow output. The device was designed with 2 chambers (mainly the lower one with dust particles and the upper one for mixing chamber). The mixed particles with air passed to chamber 2 through a cup nozzle with variable distance length for the gap as shown in figure 1 .

To evaluate the design, the flow simulation software from soildworks was used with the following parameters:

- Sand particles were used as spheres with 5 micrometers diameters.

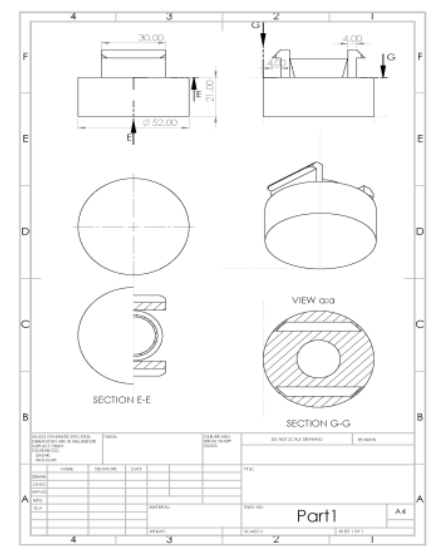

Part 1

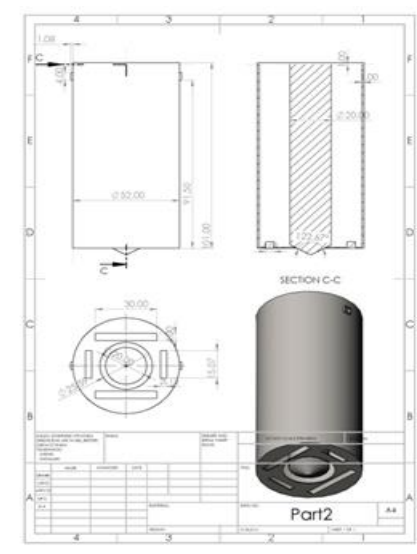

Part 2

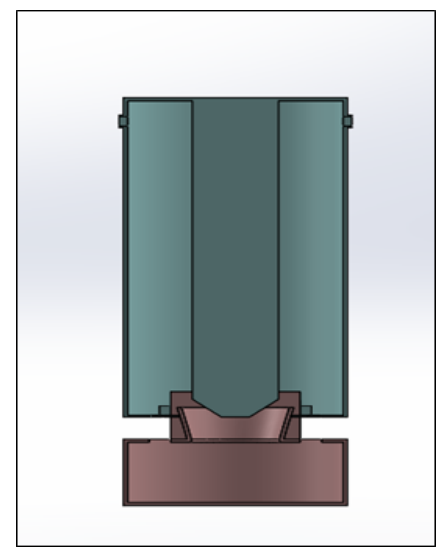

Cross section

Figure 1:Schematics cross section for spray device-3

characteristic with existing product and environmentfriendly [17-23].

The current project aims for estimating the aerodynamics behavior of aerosols/dusts using a simulations approach. Solidwarks software was used in the design of several spraying devices, starting
- Humidity was set at $50 \%$.

- Air flow was mainly from the main input holes direct to the mixing chambers. While the other 2 inputs holes were used to prevent cyclone effect in corners. 
- Out flow has 2 holes in the top of the device.

\section{Simulation of Aerodynamics Behavior of Aerosols/Dusts Particle Transport}

In Lagrangian approach framework individual particles are tracked as they move through computational domain in which the motion of any particle could be described according to Newton's $2^{\text {nd }}$ law as:

$\frac{\mathrm{dup}}{\mathrm{dt}}=\frac{\mathrm{FD}}{\mathrm{mp}}+\mathrm{a}$

where up represents particle velocity, FD represents the drag force, $\mathrm{mp}$ is particle mass and $a$ represents accelerations due to the forces other than drag force (including gravity, electrostatic force, turbulence effect on particle transport and deposition) is exerted through the fluctuation of the gas velocity, which leads to fluctuation of the drag force FD [5]. Generally drag force is expressed by Stokes law: $\mathrm{FD}=\frac{3 \pi \mu \mathrm{dp}}{\mathrm{Cc}}(\mathrm{U}-\mathrm{Up})$

where $\mathrm{u}$ is local gas velocity; $\mathbf{d p}$ is the particle diameter, $\mu$ is the dynamic viscosity of the gas, $\mathrm{Cc}$ is the Cunningham slip correction factor. The Stokes law applies based on particle diameter, Reynolds number, and gas-particle relative velocity (also known as the slip velocity), which is much smaller than unity.

Particle deposition and transport could be described in Eulerian perspective. The aerosol concentration transport equation in the Eulerian approach is:

$\frac{\partial \rho m}{\partial t}+\nabla \cdot(\rho \boldsymbol{m} \boldsymbol{V m})=0$

$\frac{\partial(\rho m \boldsymbol{V} m)}{\partial t}+\nabla \cdot(\rho \boldsymbol{m} \boldsymbol{V} \boldsymbol{m} \boldsymbol{V m})=-\nabla p+\nabla \cdot(\mu \mathrm{m} \nabla \boldsymbol{V} \boldsymbol{m})(4)$ where $V m, \rho m$, and $\mu \mathrm{m}$ represent the velocity, density, and viscosity, respectively, of the gaseous mixture comprising of air $\left(\mathrm{O}_{2}, \mathrm{CO}_{2}\right.$, and $\left.\mathrm{N}_{2}\right)$. $t$ and $\mathrm{p}$ represents the time and pressure respectively. The mixture density and viscosity are determined from the below equations:

$\rho m=\frac{1}{\sum_{i} \frac{Y i}{\rho i}}(5)$

$\mu \mathrm{m}=\sum \quad Y i \mu \mathrm{i} \quad(6)$

where suffix i represents the properties associated with the $i^{\text {th }}$ gaseous species in the mixture and $\mathrm{Yi}$ represents the mass fraction of the $\mathrm{i}^{\text {th }}$ gaseous species under constraint that $\sum \mathrm{i} Y \mathrm{i}=1$.

Transport of the different gas species within the air mixture, due to diffusive exchange across the oscillating wall, is modeled using individual species transport equations: $\frac{\partial(\rho m \boldsymbol{Y i})}{\partial t}+\nabla \cdot(\rho \boldsymbol{m} \boldsymbol{V m} \boldsymbol{Y} \boldsymbol{i})=\nabla \cdot(\rho m \operatorname{Di} \nabla \mathbf{Y i})(7)$.

The term $\mathrm{Di}$ in equation (7) represents the effective particle diffusivity which is a function of Brownian motion and eddy diffusivity, as shown in equation (8):

$\mathbf{D} i=\rho(D+\boldsymbol{\varepsilon p})(8)$

where $\varepsilon p$ is the eddy diffusivity and $D$ represents the molecular diffusivity [5].

In general, concentration of aerosol is very low, so, we neglect the displacement of the gas by particles also the particle-particle interaction. By using the Eulerian approach, concentration of particle is counted as a scalar quantity, which is represented by equation (7). The scalar equation could be solved in the flow field simultaneously. The Eulerian approach is more suitable for ultrafine particles In comparison with the Lagrangian modeling, where the inertia is negligible, however, the effect of Brownian motion is significant. Particle transport and deposition are strongly affected by turbulence, as turbulent dispersion of particles is simulated with the Lagrangian approach, by using an instantaneous gas velocity in equation (6) instead of the time-averaged velocity.

The instantaneous gas velocity includes a fluctuating component $u^{\prime}$ :

$\mathrm{U}=\mathrm{u}^{`}+\overline{\mathrm{u}}(9)$

as $u$ represents the time-averaged velocity of the turbulent flow field. The fluctuation velocity u' can assume to follow a Gaussian probability distribution with zero mean $[5,6]$.

With isotropic models ( $\mathrm{k}-\varepsilon$ ), the fluctuation velocity is:

$\mathrm{u}^{\prime}=2 \sqrt{\mathrm{K \zeta}}$ (10)

where $\zeta$ is a normally distributed random vector with a unity variance and $\mathrm{k}$ is the turbulence kinetic energy. The turbulence kinetic energy $\mathrm{k}$ is known once the flow field is solved. The fluctuation velocity will be anisotropic when an anisotropic turbulence model like Reynolds stress transport model is used, which could be gained from the solution of the flow field.

Flow simulations of solidworks package were used to study aerosol deposition in device-3. In the near-wall regions and particles more than 1 million polyhedron mesh cells were generated with high mesh density. A Reynolds stress turbulent model (RSM) was used in simulations of the flow field. Via 
Lagrangian particle tracking particle deposition was simulated with a turbulent dispersion model was included in the commercial flow simulations of solidworks package. Locations of particle deposition on the device walls were visualized based on the simulation for different particle sizes and distance between the nozzles (as will be discussed in next section).

\section{Simulation Results and Discussion}

\subsection{Case-1}

The mass flow rate $=0.5 \mathrm{~kg} / \mathrm{s}$, the distance between cup and pin of part $2=6.6 \mathrm{~mm}$. Figure 2 shows schematic cross-section simulation of the air flow profile without particles between the input and the output for spray device-3. A smooth flow was noted. Where air is moving through the device in uniform way In figure 3, the particles were added into the lower chamber as pores body with grain size of 5 micrometers and low bonding force that

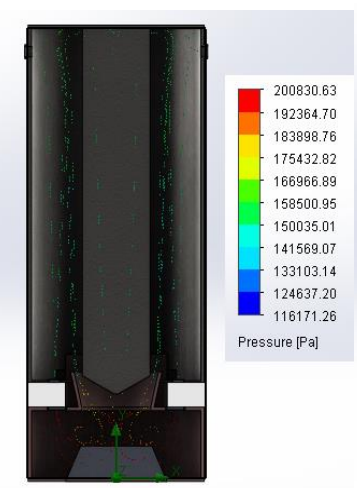

Air flow profile

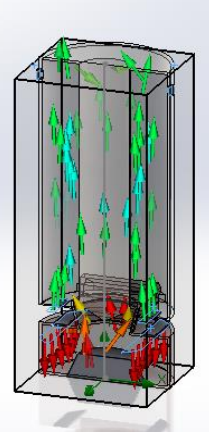

Air flow profile 3D

Fig. 2: Schematics Cross-section Simulation of Air Flow Profile without Particles between Input and Output for Spray Device-3

can be moved from the flow of air two and threedimensional profiles of particles with air showed uniformities, but with some turbulence in flow can

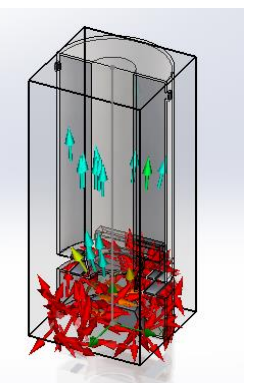

Particles flow profiles profile 2D

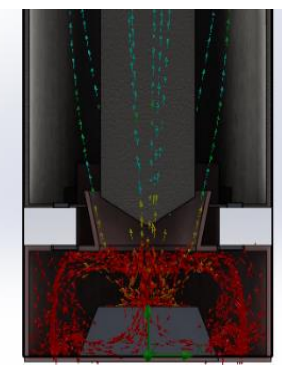

Particles flow profile with air profile $2 \mathrm{D}$

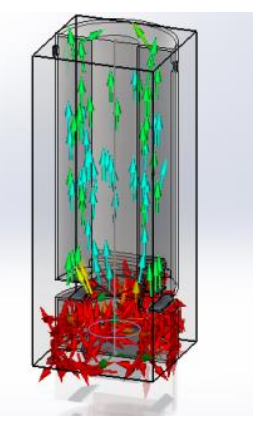

Air and particles flow

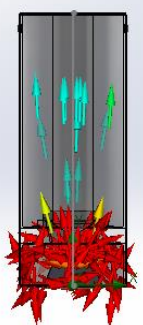

Particles flow profile 2D

Fig. 3: Schematics Cross-section Simulation of Air Flow Profile with Particles between Input and Output for Spray Device-3
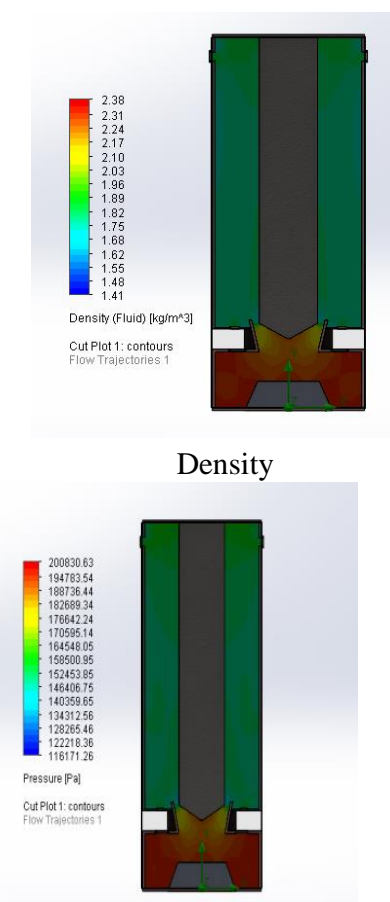

Pressure
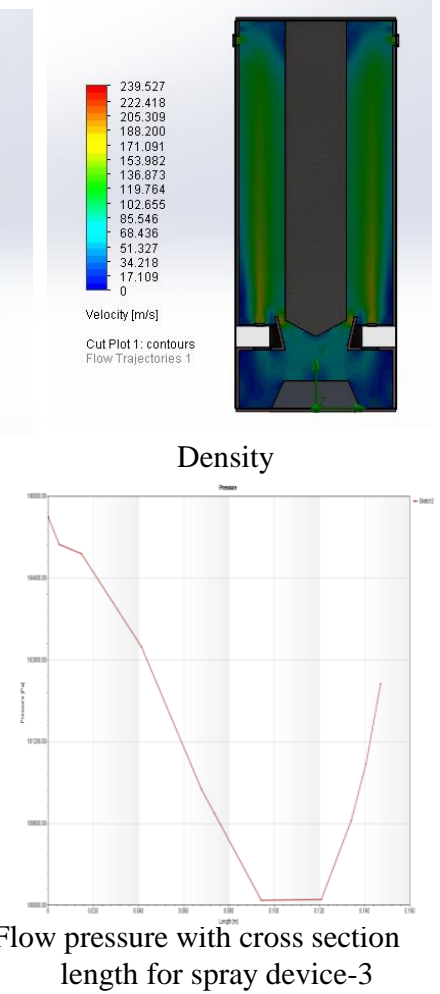

Fig. 4: Change in Flow Pressure, Velocity and Density between Input and Output for Spray Device-3

be seen specially during transportation of particles by the air stream in the except of the first chamber of the device- 3 . 
Figure 4 shows the change in flow pressure, velocity and density between input and output for spray device- 3 in a cross section. The pressure distribution was uniform distributed through the device.

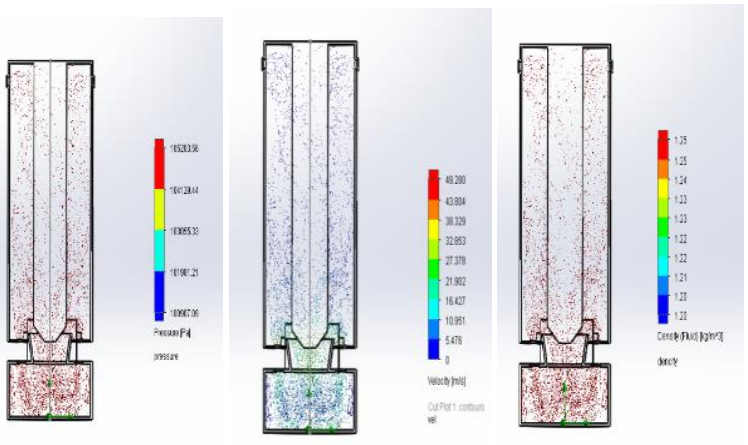

Fig. 5: Schematics Cross-section Simulation of Air Flow Profile without Particles between Input and Output for Spray Device-3

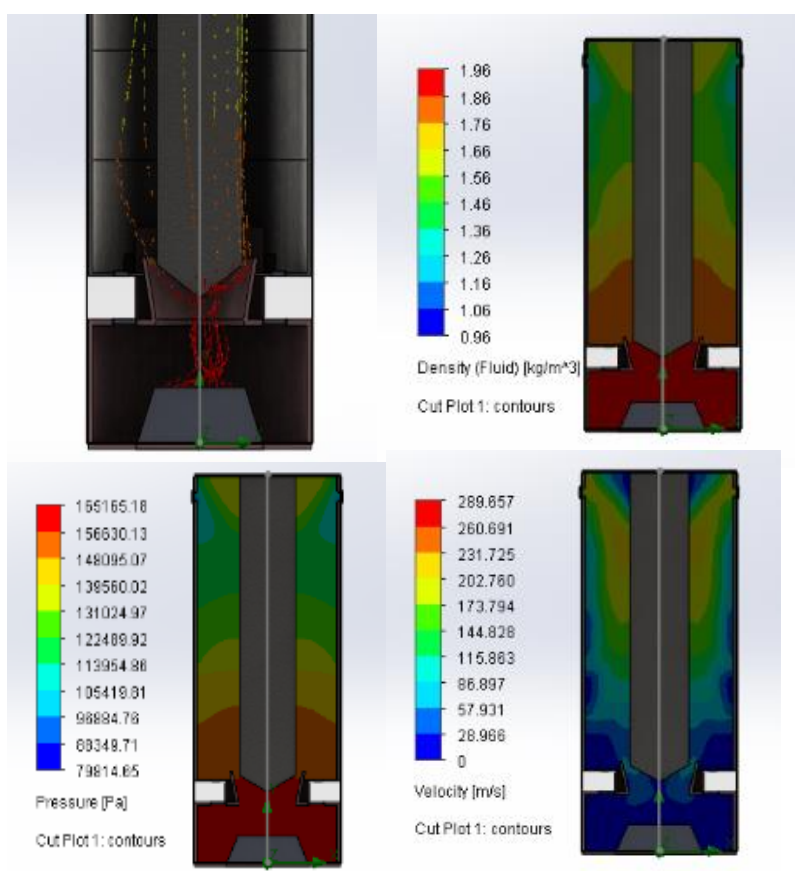

Fig. 6: Schematic cross section simulation of air flow profile with particle between input and output for spray device-3

\subsection{Case-2}

The mass flow rate $=1 \mathrm{~kg} / \mathrm{s}$, the distance between cup and pin of part $2=6.6 \mathrm{~mm}$.

The simulation of air flow profile without particles between input and output for spray device- 3 cross section was shown in Figure 5. The increase of mass flow rate increased the pressure inside the device and increased the amount of air that entered from the 2 secondary inlets.

The addition of dust particles to the simulation is seen in figures 6 and 7, with results for the whole device pressure, velocity, and density. These findings strengthened the conclusion that device- 3 had better performance.

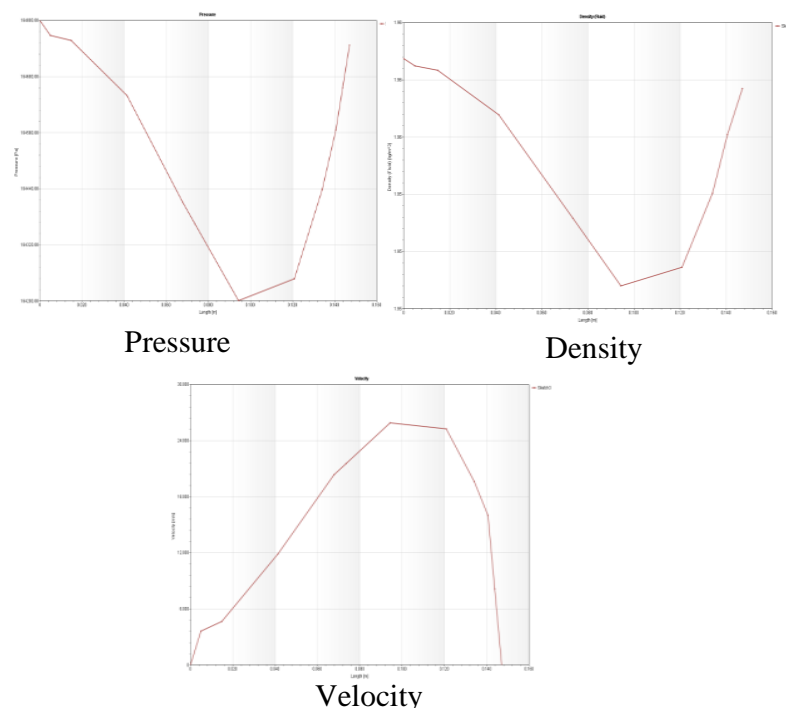

Fig. 7: Change in Flow Pressure, Velocity and Density with Cross-section Length for Spray Device-3

\subsection{Case-3}

The mass flow rate $=1 \mathrm{~kg} / \mathrm{s}$, the distance between cup and pin of part $2=6.6 \mathrm{~mm}$.

Figures 8-10 show results with mass flow rate of $1.5 \mathrm{~kg} / \mathrm{s}$ and $6.6 \mathrm{~mm}$ distance which is 2 times more than in case- 1 . The result of pressure

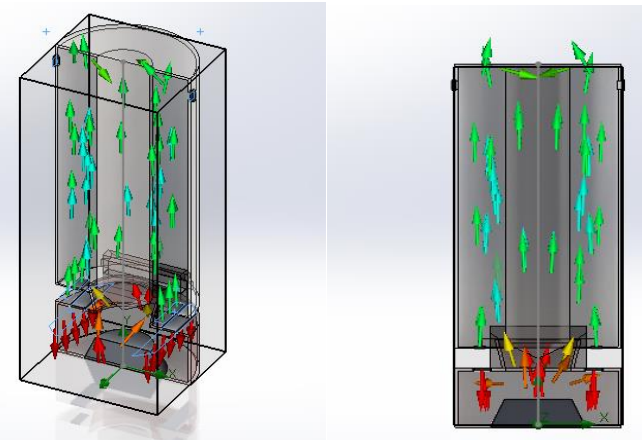

Fig. 8: Schematics Cross-section Simulation of Air Flow Profile without Particles between Input and Output for Spray Device-3 
indicated that the increase of pressure had increased not only the movement and the velocity of particles, but also the amount of it with a uniform distribution through the total length of the device. Figure 18 shows the uniform change in flow pressure, velocity and density with cross-section.

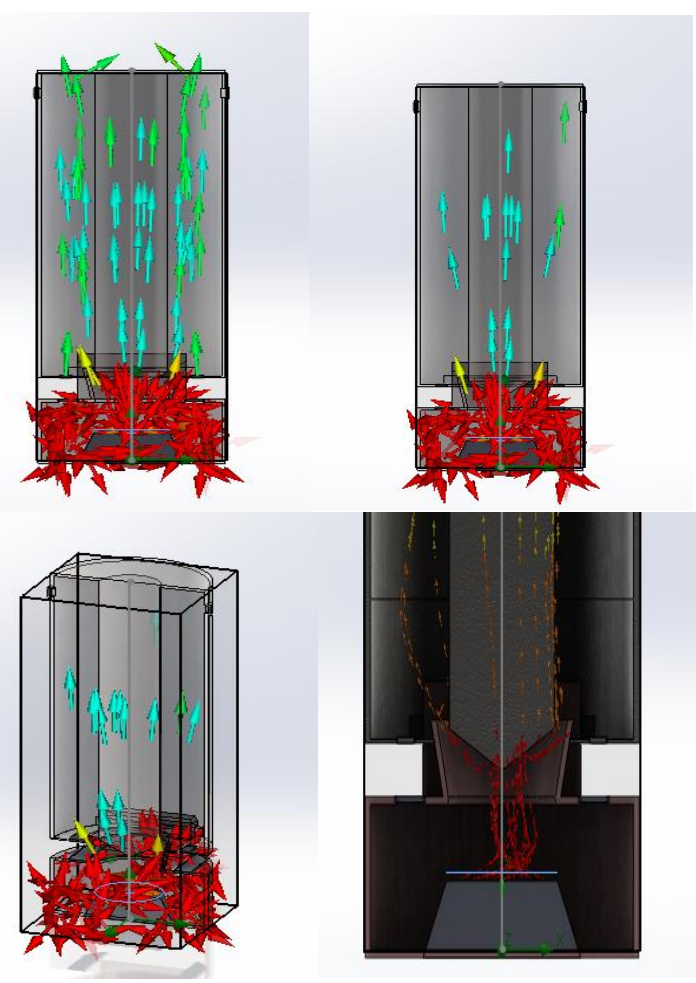

Fig. 9: Schematics Cross-section Simulation of Air Flow Profile with Particles between Input and Output for Spray Device-3

\subsection{Case-4}

The mass flow rate $=0.5 \mathrm{~kg} / \mathrm{s}$, the distance between cup and pin of part $2=3.3 \mathrm{~mm}$.

Device-3 design was modified mainly by changing the distance from $6.6 \mathrm{~mm}$ to $3.3 \mathrm{~mm}$ to investigate the influence of input of particles and airflow gap, and to minimize the eddy current flow streams which reduced the mixing between particles and air flow efficiency for the $0.5 \mathrm{~kg} / \mathrm{s}$ mass flow rate. Figures 12-14 show the air flow patterns with and without dust particles, velocity, pressure, density, vortices flow profiles and diagram through the total length. Result showed a better performance than device-3 with higher speed and pressure. this can be noted from the uniform distribution of particles transformed from the lower chamber to the second one, the air particles mixture during the second chamber shows uniformity with laminar flow to the outlet of the device.
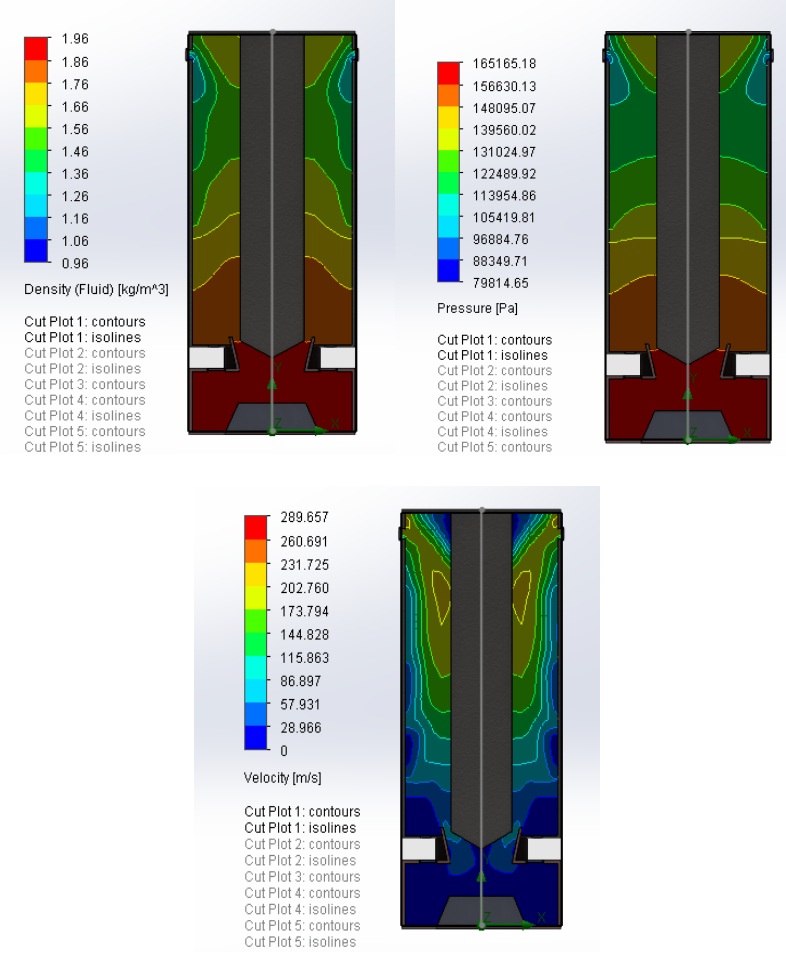

Fig. 10: Change in Flow Pressure, Velocity and Density between Input and Output for Spray Device-3

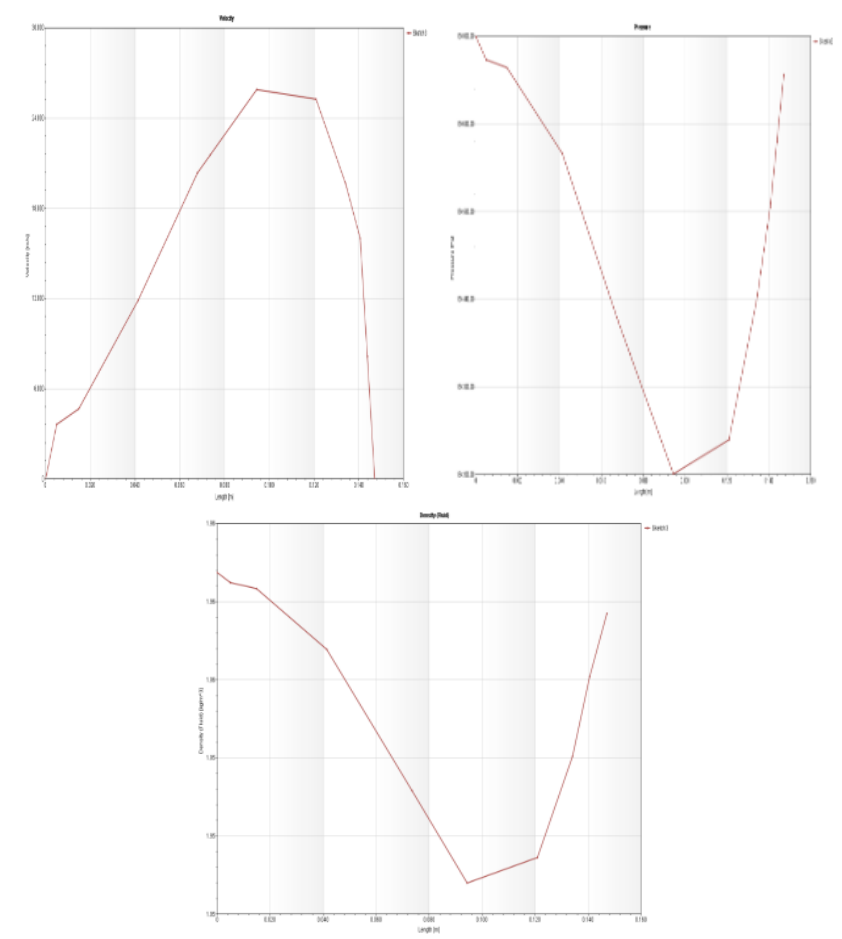

Fig. 11: Change in Flow Pressure, Velocity and Density with Cross-section Length for Spray Device-3 

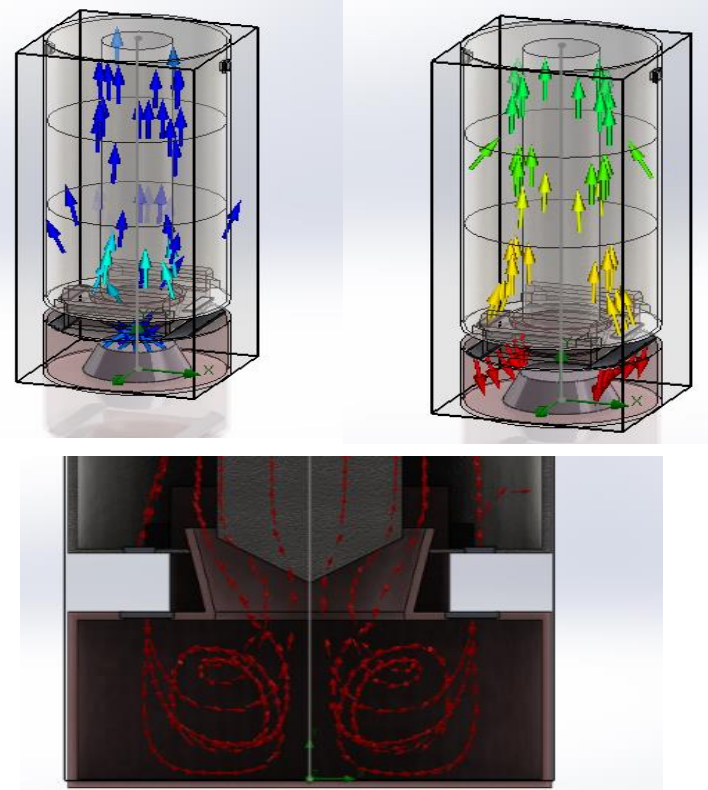

Fig. 12 Schematics Cross-section Simulation of Air Flow Profile without Particles between Input and Output for Spray Device-4
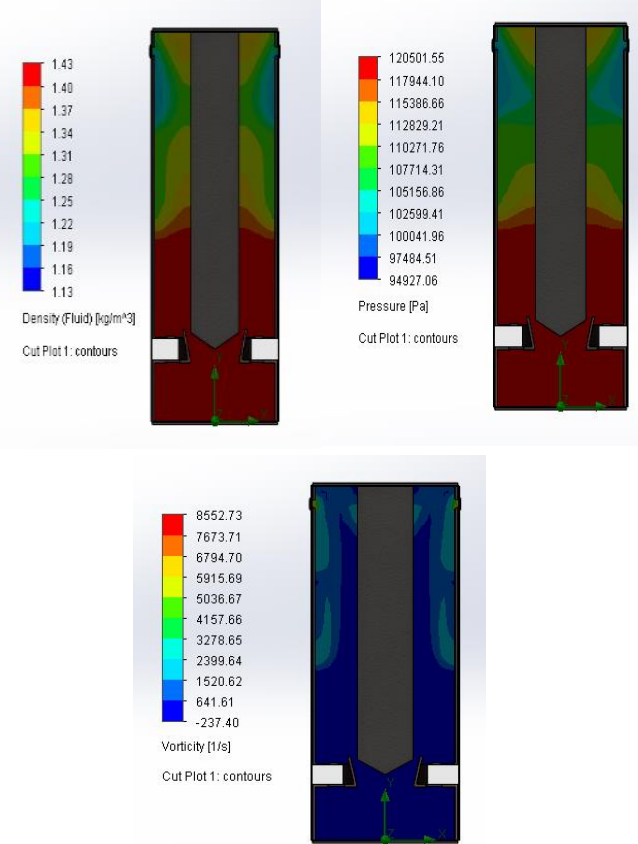

Fig. 14: Change in Flow Pressure, Velocity and Density between Input and Output for Spray Device-4

\subsection{Case-5}

The mass flow rate $=1 \mathrm{~kg} / \mathrm{s}$, the distance between cup and pin of part $2=3.3 \mathrm{~mm}$.
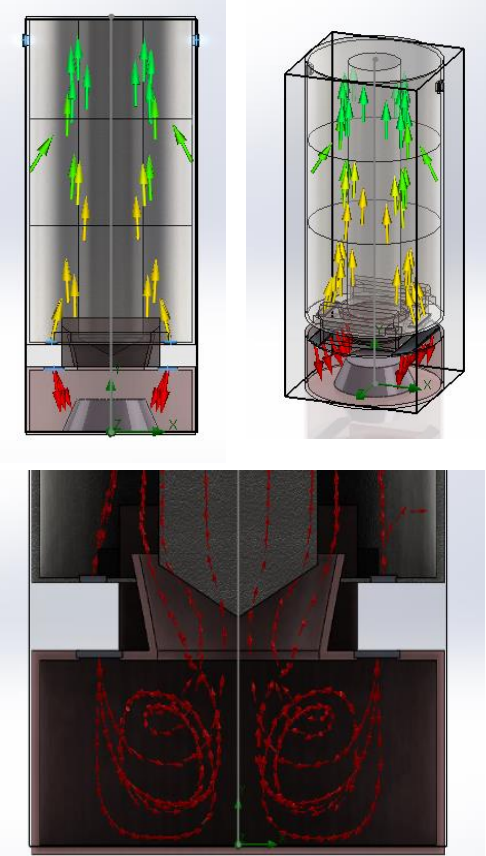

Fig. 15: Schematics Cross-section Simulation of Air Flow Profile without Particles between Input and Output for Spray Device-4
Fig. 13: Schematics Cross-section Simulation of Air Flow Profile with Particles between Input and Output for Spray Device-3 
Increasing the mass flow rate to $1 \mathrm{~kg} / \mathrm{s}$ had increased the amount of the transported particles, the pressure inside the device, and reduced the eddy current flow as shown in figures 15-18.chamber I shows turbulent flow with strong mixing and transmission of the particles, the increase of pressure during movement to chamber 2 indicate increase in amount of transmitted particle to the output of the device.

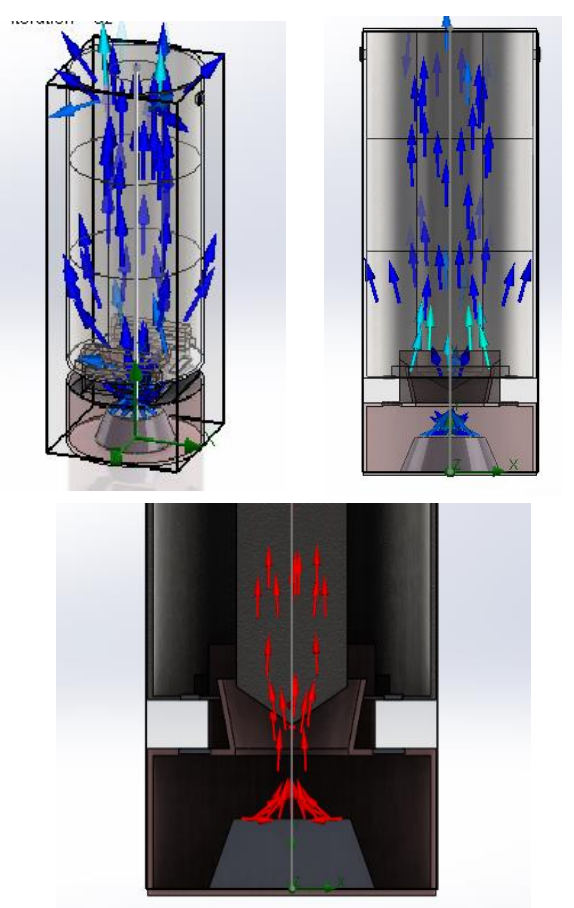

Fig. 16: Schematic Cross-section Simulation of Air Flow Profile with Particles between Input and Output for Spray Device-4
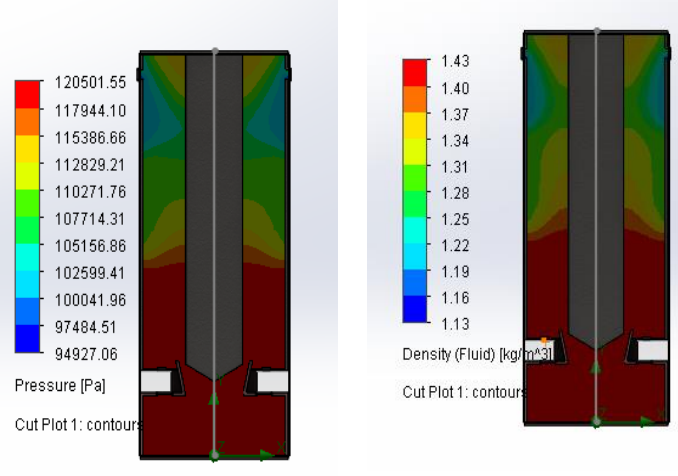

Fig. 17: Change in Flow Pressure, Velocity, Vorticity and Density between Input and Output for Spray Device-4

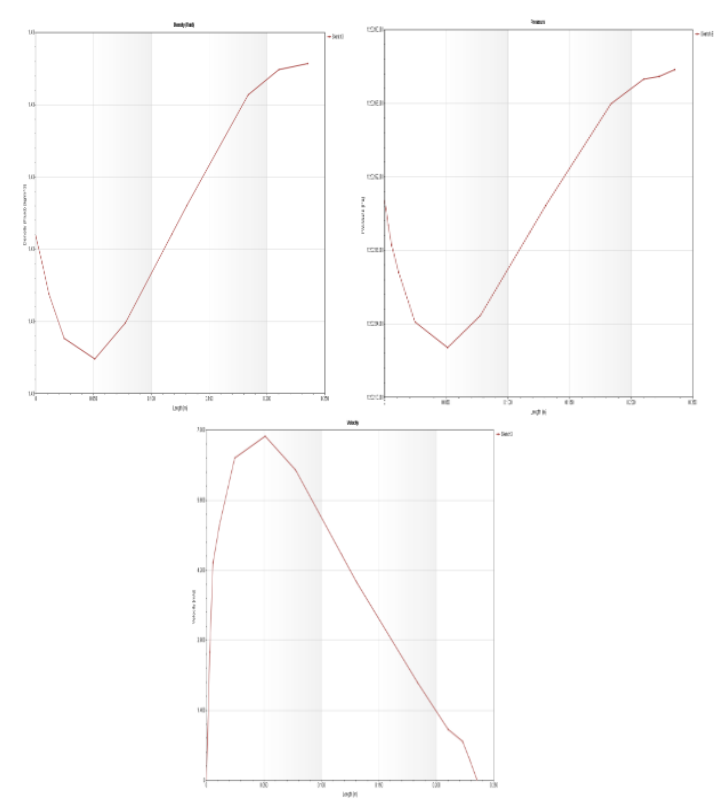

Fig. 18: Change in Flow Pressure, Velocity and Density with Cross Section Length for Spray Device-4
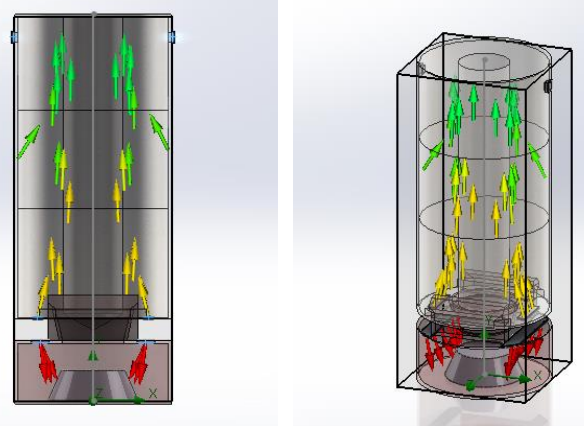

Fig. 19: Schematics Cross-section Simulation of Air Flow Profile without Particles between Input and Output for Spray Device-4
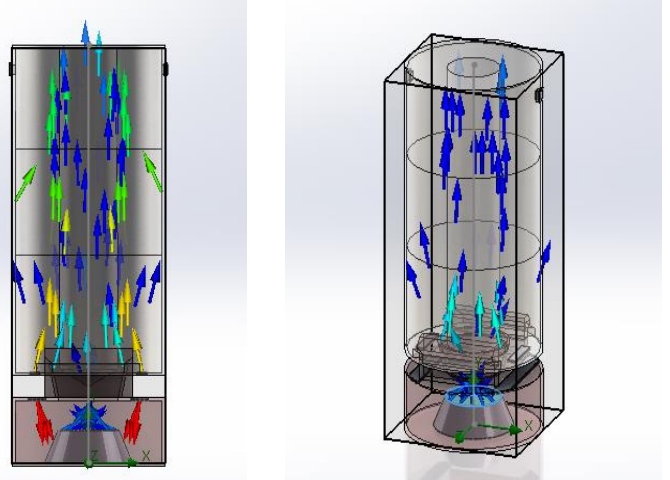

Fig. 20: Schematics Cross-section Simulation of Air Flow Profile with Particles between Input and Output for Spray Device-4 

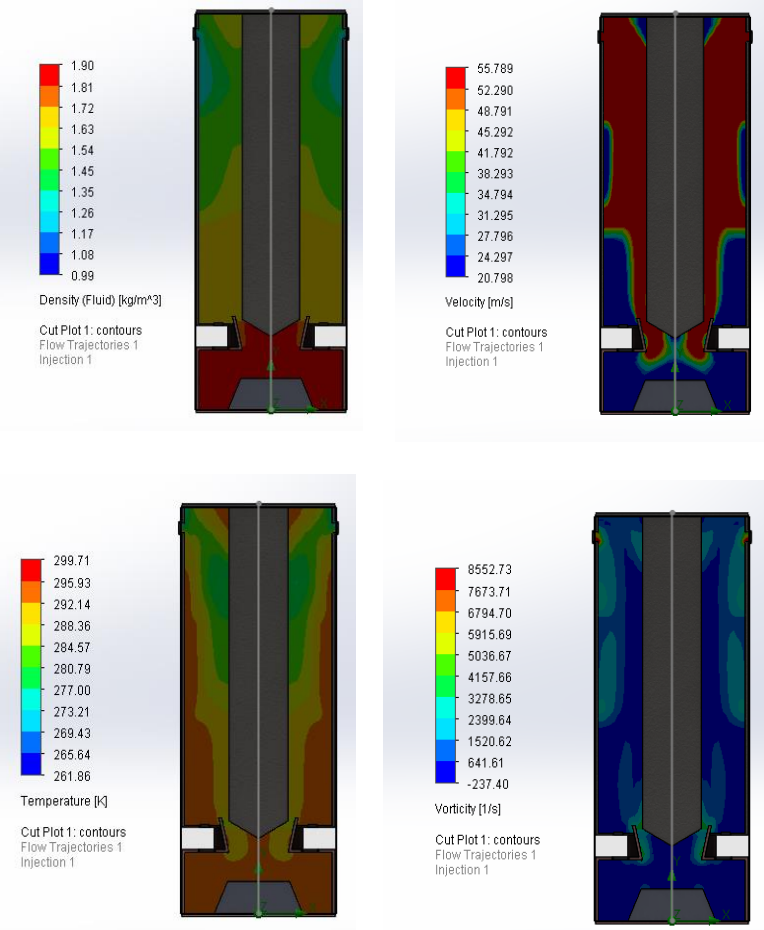

Fig. 21: Change in Flow Pressure, Velocity, Vorticity and Density between Input and Output for Spray Device-4
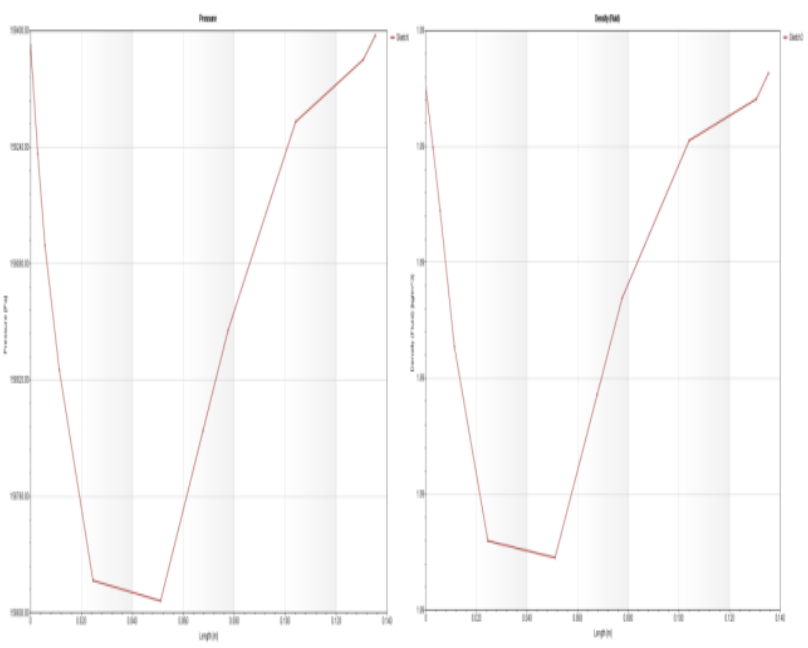

Fig. 22: Change in Flow Pressure, Velocity and Density with Cross Section Length for Spray Device-4

\section{Conclusion}

From the previous results and discussion, several conclusions were found:

- It is important to understand the relations between aerosol dust particles and air flow, for several reasons, specially health and environmental issues.

- To evaluate the relation between aerosol dust particles and air flow several spray devices were designed and tested using flow simulation software from soildworks with the different parameters.

- Spray device-3 with case-6 (mass flow rate $=1.5 \mathrm{~kg} / \mathrm{s}$, the distance between cup and pin of part $2=3.3 \mathrm{~mm}$ ) showed the best performance outputs between particles and airflow with high pressure, particles velocity and less eddy current flow.

- In general, increasing the mass flow rate had increased the particles' velocity and pressure in all of the designed spray devices.

- Using 2 main air inlets and 2 secondary inlets improved the air particles mixing and reduced turbulent cyclone effects.

- Solid works packages could be used effectively to design and simulate several dynamic systems compared to other complex CFD software's, also could be used in educational case studies.

The final designed spray device- 3 would be used as a pollination device in date palm tree pollination and capable of simulating aerosols aerodynamic behavior. cooperation and contribution. We are looking forward to seeing you at the Conference.

References:

[1] Hadadin N.A., Tarawneh Z.S. Environmental issues in Jordan, Solutions and Recommendations. American Journal of Environmental Sciences. 306;3(1): 2007.

[2] Regional euro-mediterranean programme for the environment (SMAP). National Workshop Environmental Policy Integration and SMAP III Documentation References1997.

[3] Hussein T., Abu Al-Ruz R., Petäjä T., Junninen H., Arafah D., Hämeri K., et al. Local air pollution versus short-range transported dust episodes: A Comparative Study for Submicron Particle Number Concentration. Aerosol and Air Quality Research. 109-1;11: 92011.

[4] Bathmanabhan S., Madanaya S. Analysis and interpretation of particulate matter - PM10, PM2.5 and PM1 emissions from the heterogeneous traffic near an urban roadway. Atmospheric Pollution Research. 2010;1:184-94.

[5] Yingiie TANG et al. Computational fluid dynamics simulation of aerosol transport and depositionFront. Environ. Sci. Engin. China 2011, 5(3): $362-377$ 
[6] Aranyak Chakravarty, Neelesh A. Patankar, and Mahesh V. Panchagnula; " Aerosol transport in a breathing alveolus" Phys. Fluids 31, (2019).

[7] WHO. Ambient air pollution database, 20082012; WHO country profiles 2009.

[8] Chen P.S. Ambient influenza and avian influenza virus during dust storm days and background days. Environmental Health Perspective. 2010;118:12116. $\mathrm{s}$

[9] Schweitzera M.D., Calzadillab A.S., Salamoa O., Sharific A., Kumard N., Holt G., et al. Lung health in era of climate change and dust storms. Environmental Research. 2018;163:36-42.

[10] Maki T. Phylogenetic analysis of atmospheric halotolerant bacterial communities at high altitude in an Asian dust (KOSA) arrival region, Suzu city. Scientific Total Environment. 2010;408:4556-62.

[11] Zhai Y., Li X., Wang T., Wang B., Li C., Zeng $\mathrm{G}$. A review on airborne microorganisms in particulate matters: Composition, characteristics and influence factors. Environment International. 2018;113:74-90.

[12] Sandstrom T., Forsberg B. Desert dust: an unrecognized source of dangerous air pollution? Epidemiology. 2008;19:808-9.

[13] Huang Q. Effects of water soluble PM2.5 extracts exposure on human lung epithelial cells (A549): a proteomic study. Journal of Applied Toxicology. 2014;34:675-87.

[14] Ababsa M. Atlas of Jordan. Ababsa M, editor. Beyrouth: Presses de 1'Ifpo, Institut français du Proche-Orient; 2013.

[15] Rantanen J, Khinast J. The Future of pharmaceutical manufacturing sciences. Journal of Pharmaceutical Sciences.;104(11):3612-38;2015.

[16] Radhakrishnan A. , Kuppusamy G., Karri V. Spray bandage strategy in topical drug delivery. Journal of Drug Delivery Science and Technology. 2018;43:113-21.
[17] Kaltenbach C, Laurien E. CFD simulation of spray cooling in the model containment THAI. Nuclear Engineering and Design. 359-71;328,2018:.

[18] Kumar H., Jain R. Review: The role of computational simulation in understanding the postoperative sinonasal environment. Clinical Biomechanics. 20418; (in press):https://doi.org/10.1016/j.clinbiomech..02.001, 2018.

[19] Lizal F, Jedelsky J, Morgan K, Bauer K, Llop J, Cossio U, et al. Experimental methods for flow and aerosol measurements in human airways and their replicas. European Journal of Pharmaceutical Sciences.;113:95-1312018.

[20] Frederix EMA, Kuczaj AK, Nordlund M, Bělka M, Lizal F, Jedelský J, et al. Simulation of sizedependent aerosol deposition in a realistic model of the upper human airways. Journal of Aerosol Science. 29-45;1152018:.

[21] Bass K, Worth Longest P. Recommendations for simulating microparticle deposition at conditions similar to the upper airways with two-equation turbulence models. Journal of Aerosol Science. 3150;1192018:

[22] Maddineni AK, Das D, Damodaran RM. Airborne particle capture by fibrous filter media under collision effect: A CFD-based approach. Separation and Purification Technology. 1-10;1932018:.

[23] Al-Waked R., Groenhout N., Partridge L., Nasif M. S. Indoor air environment of a shopping centre carpark: CFD ventilation study. Universal Journal of Mechanical Engineering. 113-23;5(4): 2017.

[24] Hasnain S., Nasif M., Pao W., Al-Waked R. Numerical investigation of smoke contamination in atrium upper balconies at different down stand depths. Building Simulation. 365-81;10(3): 2017

[25] Guessab A., Aris A., Numerical Analysis of CPU with Heat Sink base of Copper Core using CFD International Journal of Mechanics, pp.144-148, Volume 13, 2019

\section{Creative Commons Attribution License 4.0 (Attribution 4.0 International, CC BY 4.0)}

This article is published under the terms of the Creative Commons Attribution License 4.0

https://creativecommons.org/licenses/by/4.0/deed.en_US 